\title{
Determinants and differentials of postpartum amenorrhea associated with breastfeeding among women in Bihar, India
}

\author{
Brajesh $^{1}$, Mukesh Ranjan $^{1}$, Nagdeve D.A. ${ }^{2}$, Chander Shekhar ${ }^{2}$
}

\author{
${ }^{1}$ Research Scholar, International Institute for Population Sciences, Deonar, Govandi Station Road, Mumbai, \\ Maharashtra, India \\ ${ }^{2}$ Department of fertility Studies, International Institute for Population Sciences, Deonar, Govandi Station, Mumbai, \\ Maharashtra, India
}

Received: 4 November 2015

Revised: 11 December 2015

Accepted: 15 December 2015

\section{*Correspondence:}

Brajesh,

E-mail: iipsmumbai2012@gmail.com

Copyright: (C) the author(s), publisher and licensee Medip Academy. This is an open-access article distributed under the terms of the Creative Commons Attribution Non-Commercial License, which permits unrestricted non-commercial use, distribution, and reproduction in any medium, provided the original work is properly cited.

\begin{abstract}
Background: Postpartum amenorrhea is considered to be the conception variable and its affect natural fertility by lengthening the inter-live birth interval. In societies where the fertility is not regulated through the use of contraception method there amenorrhea period can exert a dominant fertility inhibiting effect on fertility. In this paper we check differentials in duration of breastfeeding and Postpartum Amenorrhea (PPA), and to estimate mean duration of Postpartum Amenorrhea (PPA) associated with breastfeeding with influence of Scio-economic and demographic factors of ever-married woman who had given at least one but last birth in Bihar, India.

Methods: Kaplan Meier Survival method use to estimate the duration of breastfeeding and postpartum amenorrhea and multivariate Cox proportional hazard model used to measure the effect of each category of each variable on the hazard function while controlling for the effects of other variables (and their categories) included in the model.

Results: Duration of breastfeeding, parity, residence, contraceptive use have a significant impact on duration of postpartum amenorrhea (PPA) and empirical evidence indicates that longer and more frequent breastfeeding may increase the length of an ovulatory period. Mothers with a BMI greater than $18.5 \mathrm{~kg} / \mathrm{m}^{2}$ resume ovulation faster and high mean for duration of breastfeeding than those with a lower BMI.

Conclusions: Parity, age of mothers, survival status of child and socio-economic status of mothers are found to be the main influencing factors for the timing of postpartum amenorrhea and also duration of breastfeeding among mothers., it is expected that the findings may help in designing appropriate policies and programs for improving mothers' and children's health as well as for reducing the existing fertility level of a region where contraceptive practices is low.
\end{abstract}

Keywords: Postpartum amenorrhea, Breastfeeding, Kaplan-Meier, Cox-Proportional hazard, Body mass index

\section{INTRODUCTION}

Postpartum amenorrhea (PPA) is defined as a temporary infecundable period immediately following of pregnancy into a live birth, still birth or a late term abortion. It is considered as the duration variable. It is directly related to the levels of fertility. It affects the fertility by lengthening the period of conception. PPA is the period from the end of a woman's pregnancy until the time that she begins to menstruate. The timing of occurrence of first menstruation after delivery is known as the duration of PPA, and women are supposed to be in safe period from possible conception.

Several literatures have shown that there are many variables that directly affect natural fertility. In fact, 
Davis and Blake (1956) pointed out eleven key variables, and these variables are categorized into three main headings as intercourse, conception, and gestation variables. ${ }^{1}$ These variables are known as intermediate variables that affect natural fertility. The other associated variables such as biomedical, demographic and socioeconomic factors are termed as explanatory variables. These variables also influence fertility through the route of intermediate variables. It is one of the main proximate determinants of fertility that affect natural fertility directly. PPA variable is considered to be the conception variable, affect natural fertility by lengthening the inter-live birth interval. ${ }^{2,3}$

There are different societies where fertility is not regulated through the use of contraception; amenorrhea period can exert a dominant fertility inhibiting effect since a large number of women's reproductive life span spent in an amenorrhea state. Some empirical evidences also have argued that PPA period is positively associated with age of mother and her parity. It is well-established fact that education of mothers shows an inverse association on the duration of postpartum amenorrhea. Undernourished nursing mothers were found to have a longer duration of postpartum amenorrhea relative to better nourished mothers (Nath, Goswami, 1996). ${ }^{4}$ PPA period also largely varied according to caste/ethnicity, residential status, as well as socio-economic status. Studies further argued a secular declining trend in amenorrhea period over time. However, the amenorrhea duration varied within and between the populations pertaining to the characteristics of mother and her child. It is obvious fact that PPA is becoming an important variable to study the fertility behavior and mothers' health status in the society especially among women in the higher fertility experienced populations. However, many mechanisms by which breastfeeding behavior and other factors produce variability in the length of an ovulatory period, and thus in the resumption of menses across populations as well as within a population in different social and cultural groups, remain either unspecified or unknown. They are probably associated with biological characteristics and specific social structures and implicit or explicit social norms.

According to some studies the length of PPA was shorter for Muslim than that of Hindu mothers. The duration of breastfeeding and PPA seems to be the most significant variable in explaining the resumption of menses among Bihar's women. Although the relationship between breastfeeding and amenorrhea depends heavily on the frequency of nursing, factors such as parity, use of contraception, standard of living, age of mother, child survival status, partner's education and occupation, caste, religion, region, birth interval, mother occupation and especially women's education also play an important role in the return of menses.

This procedure will allow us to address the problem of confounding influences of social, demographic and biological factors in the mechanisms underlying postpartum infertility, and to capture the heterogeneity of women's behavior about breastfeeding (Islam \& Islam, 1993)5. Therefore a comprehensive study is needed to document such issues where a high fertility experience is a natural phenomenon in the society. Since, Bihar has experienced higher fertility as compared to the other states of India. Therefore, the present study has undertaken to investigate the determinants and differentials of amenorrhea and its association with breastfeeding in Bihar.

\section{Review of literature}

Davis and Blake (1956) identified eleven intermediate variables from which all these factors affect to human fertility directly. ${ }^{1}$ These eleven intermediate variables are based on the different socio-economic, biological and demographical factors. These intermediate variables grouped into three categories: intercourse variables, conception variables and gestation variables. From the 11 intermediate variables given by Davis and Blake, later on Henry, L (1961) describes about the influence of breastfeeding on fertility or equivalently to fact that the postpartum amenorrhea depends on the breastfeeding. ${ }^{6}$ Among several proximate determinants of fertility, PPA is one of the proximate determinants of fertility which directly affect to natural fertility (Bongaarts, 1978). ${ }^{7}$ Henry identified four inhibiting intermediate variables i.e. postpartum infecundable period, waiting time to conception, intrauterine mortality, and permanent mortality. Therefore the societies where the use of contraception is not prevalent, the duration of PPA plays important roles in reducing fertility by increasing inter live birth interval (Potter et al., 1965). ${ }^{9}$ However this relationship was emphasized Henry and later by Bongaarts in (1978).

Bongaarts in 1978 and 1983, described these intermediate variables by Davis and Blake in 1956 and Henry in 1953 and 1961 into eight basic factors called proximate determinants. $^{1,6-8}$ So, the actual fertility changes in any society are more frequently due to four factors, proportion of married women, effectiveness of contraception, induced abortion, and duration of postpartum infecundity. ${ }^{8}$ Some studies have shown that the duration of PPA has been positively related with the nutritional status of women, ${ }^{10,11}$ a lot of research has been done to assess the fertility inhibiting effects of PPA by exploring the relationship between the length of PPA and duration of breastfeeding, ${ }^{11,12}$ and frequency of breastfeeding have a strong impact on the duration of postpartum amenorrhea. $1,3,12-14$

\section{Statement of the problem}

Bihar contributes $9 \%$ of total population in India (Census, 2011). ${ }^{17}$ Half of the women in the state are under nourished as $50 \%$ of women are having normal body mass index with BMI mean (19.4). Another important 
factor is prevalence of contraceptive use (34.1\%) in Bihar which has third low Couple Protection Rate (CPR) and total fertility rate is very high as compared to other states in India. Therefore, it is imperative to study differentials of postpartum amenorrhea in a society where contraceptive use rate is very low. The PPA plays a vital role in controlling fertility by lengthening the inter-birth interval. According to the report of NFHS-3, the highest proportion $(21 \%)$ of pregnancies did not result in a live birth in Bihar. In an attempt to understand this process and its demographic significance in a better way, the purpose of this study is to investigate the causal relationship between the length of postpartum amenorrhea and breastfeeding variables as well as other demographic and socioeconomic factors that could modify the pace of both postpartum amenorrhea and breastfeeding. Therefore, present paper is undertaken with the following objectives;

1. To study the differentials in duration of breastfeeding and postpartum amenorrhea in Bihar.

2. To examine the socio-economic and demographic factors determining duration of breastfeeding in relation to some characteristics of mother and child by current status in Bihar.

3. To investigate the socio- demographic factors influencing the duration of postpartum amenorrhea in Bihar.

\section{Data source}

The analysis of data has been done from National Family Health Survey (NFHS-3) which was carried out during 2005-2006. ${ }^{15}$ The ever-married woman who had given at least one but last birth were selected for this study. The selected sample had 9502 women respondents; out of the selected sample 3818 ever-married woman who had given at least one but last birth in Bihar are selected in this study. The selected sample consists of 2316 evermarried woman in rural areas and 1520 ever-married woman in urban areas. The NFHS-3 has collected information on fertility related aspects such as duration of breastfeeding and duration of postpartum amenorrhea from the ever married women. So, the information related to breastfeeding and amenorrhea is based on only current status of the women.

\section{Dependent variable}

The duration of post-partum amenorrhea (PPA) is considered as the dependent variable. The duration of PPA is measured in completed months and also the duration of amenorrhea is grouped in five categories i.e. intervals of $0-6,7-12,13-18,19-24$ and 25 months and above. We have taken duration of breastfeeding and postpartum amenorrhea as a dependent variable and all the covariate apply for both, in case of post-partum amenorrhea breastfeeding is taken as an independent variable.

\section{Independent variables}

The independent variables included in the analysis are grouped into socio-economic and demographic variables. Socio-economic variables include place of residence, education of mother, caste/ethnicity, and religion, working status of mother, standard of living and body mass index of women. Demographic variables includes age at first marriage, age of mother at the birth of first child, current age of mother, breastfeeding duration in months, duration of breastfeeding, parity of mother, survival status of child (child loss by the mother), sex of child, delivery status, and use of contraception.

\section{METHODS}

Mean duration of postpartum amenorrhea (PPA) and breastfeeding by Kaplan-Meier survival method

Subjects were asked about their duration of postpartum amenorrhea in months. Women reporting continuance of amenorrhea on the date of interview were considered censored cases and their durations of PPA (between last delivery and survey date) were recorded and treated as censored data. Censored observation for which we have no information or observation is not known for such women. It was not known when they would resume ovulation in future after the survey date. Subjects with censored data contribute valuable information and they should not be omitted from the analysis. Survival analysis is statistical technique useful for this data. There is procedure of survival analysis, viz. follow-up KaplanMeier (KM) procedure.

The Kaplan-Meier survival analysis procedure does not rely on partitioning the observation period into smaller, time interval, rather it estimates conditional probabilities at each time point when an event occurs. There are three assumptions for this methodology. Firstly, at any time subjects who are censored have the same survival prospects as those who continue to be followed. Secondly, survival probabilities are the same for subjects recruited early and late in the study. Thirdly, the event happens at the time specified. So for study of duration of breastfeeding and postpartum amenorrhea we select Kaplan Meier estimate in Bihar, India.

\section{Cox proportional hazard model}

Univariate hazard model analysis is used to offer a measure of the effect of each variable on the duration specific probabilities of the resumption of menstruation (hazard function) in the absence of the control for other variables included in the model. ${ }^{16}$ A multivariate Cox proportional hazard model analysis is then undertaken to measure the effect of each category of each variable on the hazard function while controlling for the effects of other variables (and their categories) included in the model. Let us denote the risk of returning to menstruation 
by the equation under the Cox proportional hazard model is given below.

$$
h(t)=h_{0}(t) \exp \left(\beta_{1} x_{1}+\beta_{2} x_{2}+\beta_{3} x_{3}+\beta_{4} x_{4} \ldots \ldots \ldots .+\beta_{i} x_{i}\right)
$$

Where, $\mathrm{i}=1,2,3,4 \ldots \ldots \ldots \ldots \ldots \ldots \ldots \ldots \ldots$

Variable $\mathrm{t}$ denotes the duration (time) of the study variable.

$\mathrm{h}(\mathrm{t})$ is the hazard rate at which event occurs.

$\mathrm{h}_{0}(\mathrm{t})$ is the baseline hazard function that varies only with $\mathrm{t}$ and for which no specific function is assumed, $\mathrm{x}$ is a vector of independent variables and $\beta$ is a vector of regression parameters.

If $\beta>1$ means that the covariate has the effect of raising the hazard rate.

If $\beta<1$ then one has the opposite effect.

If $\beta=1$ then it is neutral and exerts no effect.

\section{Statistical hypothesis}

$H_{0}$ : There is not influence of covariate on duration of breastfeeding and postpartum amenorrhea.

$H_{1}$ : The covariate influence on duration of postpartum amenorrhea and breastfeeding.

\section{RESULTS}

The socio-economic, demographic and breastfeeding Bihar is presented in Table1. It can be seen from table that around two-thirds $(65 \%)$ of women had never use any contraceptive method. Majority of women (65\%) had continued breastfeeding for 0-5 months. However around $10 \%$ of women continue breastfeeding for 6- 12 months. It is also observed that less than $15 \%$ of women were continuing. Most of the women (96\%) delivered child normally whereas only $4 \%$ of women had caesarean delivery. The women were having more male child than female child.

The most of the women $(84 \%)$ were from rural areas. Most of the women (83\%) were belonging to Hindu religion and $(17 \%)$ of the women were belonging to Muslim religion. Majority of the women $(62 \%)$ were not educated and only $10 \%$ were primarily educated. More than one fourth of the women $(26 \%)$ were secondary educated and only $2 \%$ of women were highly educated.

The age distribution of women shows that $1 / 4^{\text {th }}$ of women were below 19 years of age, 35\% women were in age group of 20-29 years and $40 \%$ of women were in the age group of 30 years and above. Most of the women (95\%) were less than 19 years of age and only $5 \%$ of women were in the age 19 years and above at the time of first marriage. More than half of the women (71\%) were less than 19 years of age, $25 \%$ of the women were in 20-24 years of age and only $3 \%$ of women were in age 25 years and above at the time of age of first birth of child. Most of the women $(81 \%)$ experienced postpartum amenorrhea of 0-6 months, $13 \%$ of women reported 7-12 months of amenorrhea, less than $4 \%$ of women reported 13-18 months of postpartum amenorrhea, only $2 \%$ of women reported 19-24 months of postpartum amenorrhea and only $1 \%$ of women reported more than 25 months of postpartum amenorrhea. Three-fourths of women (75\%) have not experienced child loss, $17 \%$ of women reported 1 child loss and $9 \%$ of women reported 2 children loss. Majority of women $(76 \%)$ were not working and only $24 \%$ of women were working in Bihar.

\section{Mean duration of breastfeeding of among women}

The mean survival for breastfeeding of women by selected background characteristics who are continuing breastfeeding by duration of breastfeeding in Bihar is given in Table 2. The mean for duration of breastfeeding by the parity of women decreases from the low parity to high parity of the women (in case of parity one, mean is 22 months, median 24 months; parity 2, mean 21 months, median 18 months, parity 3-4, mean 18 months, median 19 months and parity 5 and above mean 16 months). The mean and median duration of breastfeeding is decreasing with increasing parity. By the Log rank test the association between the duration of breastfeeding and parity of women is highly significance $(\chi 2=60.622$, $\mathrm{P}<0.01)$. By the wealth index of women the mean survival time are decreasing. The women belonging to poorest, poorer and middle are having high mean for survival time as compared to richer and richest women but it is decreasing with increasing wealth quintile. The women who have normal or less body mass index have high mean for survival time (12 months) as compared to women who have more than normal body mass index (15 months).

To assess the pattern of breastfeeding, mean for survival time and survival curves were built by the Kaplan-Meier method for breastfeeding. Figure 1 shows the survival curve for duration of breastfeeding of women, according to parity of women.

The figure shows that survival function of breastfeeding by the parity of women, duration of breastfeeding decreased substantially up to 24 months, afterwards the function decreased steadily. This is indicative that older mothers with higher parity have had higher chance of survival or larger duration of breastfeeding than younger mothers others with having lower parity. The curve is slightly decreasing according to duration of breastfeeding.

Figure 2 presents the survival curve by the body mass index of women which shows the chance of survival duration of breastfeeding. It is higher in case of those 
women who are belonging to less than normal or normal body mass index and survival duration of breastfeeding are low in case of women who have more than normal body mass index.
Figure 3 depicts the survival curve of experience of child loss by mothers. It indicates that there are higher chances of breastfeeding in case of those women who had lost their child as compared to those women who have no child loss experience.

Table 1: Percent distribution of ever married women who had last but at least one child by some selected background characteristics of women and child in Bihar, India 2005-2006.

\begin{tabular}{|c|c|c|c|c|c|}
\hline Background characteristics & $\begin{array}{l}\text { No. of } \\
\text { women }\end{array}$ & Percent & Background characteristics & No. of women & Percent \\
\hline Contraceptive use & & & Age of mother & & \\
\hline Not use & 2352 & 64.5 & $<19$ years & 923 & 24.8 \\
\hline Use & 1466 & 35.5 & $20-24$ years & 703 & 17.9 \\
\hline Duration of breastfeeding & & & 25-29 years & 634 & 16.7 \\
\hline $0-5$ months & 2584 & 64.6 & 30 years and above & 1558 & 40.6 \\
\hline 6-12 months & 342 & 10.0 & Age of first marriage & & \\
\hline 13-24 months & 525 & 14.9 & $<19$ years & 2910 & 94.9 \\
\hline 25 months and above & 367 & 10.6 & $20-24$ years & 223 & 4.6 \\
\hline Parity of women & & & 25-29 years & 25 & 0.4 \\
\hline Parity 1 & 416 & 15.2 & 30 years and above & 2 & 0.1 \\
\hline parity2 & 500 & 18.2 & Age at first birth & & \\
\hline Parity 3-4 & 927 & 33.8 & $<19$ years & 1889 & 71.5 \\
\hline parity 5 and above & 900 & 32.8 & $20-24$ years & 749 & 25.3 \\
\hline Delivery status & & & 25-29 years & 92 & 2.7 \\
\hline Normal & 1472 & 96.3 & 30 years and above & 13 & 0.5 \\
\hline Caesarean & 77 & 3.7 & Postpartum amenorrhea & & \\
\hline Sex of child & & & $0-6$ months & 3170 & 80.5 \\
\hline Male & 1539 & 56.1 & 7-12 months & 421 & 12.7 \\
\hline Female & 1204 & 43.9 & 13-18 months & 121 & 3.6 \\
\hline Residence & & & 19-24 months & 63 & 1.8 \\
\hline Urban & 1502 & 16.1 & 25 months and above & 43 & 1.4 \\
\hline Rural & 2316 & 83.9 & Child loss & & \\
\hline Religion & & & No loss & 2990 & 74.7 \\
\hline Hindu & 3129 & 82.6 & One loss & 586 & 16.6 \\
\hline Muslim & 678 & 17.3 & Two plus child loss & 312 & 8.8 \\
\hline Others & 11 & 0.1 & Working condition & & \\
\hline Education level & & & Not working & 3018 & 76.5 \\
\hline No education & 2097 & 62.1 & Working & 800 & 23.5 \\
\hline Primary & 362 & 10.0 & Body mass index & & \\
\hline Secondary & 1184 & 25.5 & $<=18.5 \mathrm{~kg} / \mathrm{m}^{2}$ & 1985 & 85.2 \\
\hline Higher & 175 & 2.4 & $>18.5 \mathrm{~kg} / \mathrm{m}^{2}$ & 346 & 14.8 \\
\hline \multicolumn{6}{|l|}{ Wealth Index } \\
\hline Poorest & 803 & 26.2 & & & \\
\hline Poorer & 907 & 28.8 & & & \\
\hline Middle & 651 & 18.4 & & & \\
\hline Richer & 715 & 16 & & & \\
\hline Richest & 742 & 10.7 & & & \\
\hline
\end{tabular}


Table 2: Survival mean of breastfeeding of women by selected background characteristics who are continuing breastfeeding by duration of breastfeeding, Bihar, India 2005-2006.

\begin{tabular}{|c|c|c|c|}
\hline \multicolumn{4}{|c|}{ Mean duration of Breastfeeding } \\
\hline & Estimate & $\%$ Confidence Interval & \\
\hline \multicolumn{4}{|l|}{ Parity of women } \\
\hline Parity 1 & 21.934 & $(19.928-23.939)$ & \multirow{4}{*}{$\begin{array}{l}\text { Log Rank (Mantel-Cox) } \\
\text { (overall comparison) } \\
(\chi 2=60.622, \mathrm{p}<.001)\end{array}$} \\
\hline Parity 2 & 20.943 & $(18.551-23.336)$ & \\
\hline Parity 3-4 & 17.929 & $(16.221-19.638)$ & \\
\hline$\geq$ Parity 5 & 15.619 & $(14.087-17.152)$ & \\
\hline \multicolumn{4}{|l|}{ Wealth Index } \\
\hline Poorest & 20.21 & $(18.188-22.239)$ & \multirow{5}{*}{$\begin{array}{l}\text { Log Rank (Mantel-Cox) } \\
\text { (overall comparison) } \\
(\chi 2=231.362, p<.001)\end{array}$} \\
\hline Poorer & 16.56 & $(14.915-18.208)$ & \\
\hline Middle & 14.24 & $(12.423-16.066)$ & \\
\hline Richer & 8.955 & $(7.659-10.251)$ & \\
\hline Richest & 5.783 & $(4.787-6.779)$ & \\
\hline Body Mass Index & & & \multirow{3}{*}{$\begin{array}{l}\text { Log Rank (Mantel-Cox) } \\
\text { (overall comparison) } \\
(\chi 2=23.965, \mathrm{p}<.001)\end{array}$} \\
\hline$<=18.5 \mathrm{~kg} / \mathrm{m}^{2}$ & 12.077 & $(11.163-12.991)$ & \\
\hline$>18.5 \mathrm{~kg} / \mathrm{m}^{2}$ & 15.805 & $(14.291-16.291)$ & \\
\hline
\end{tabular}

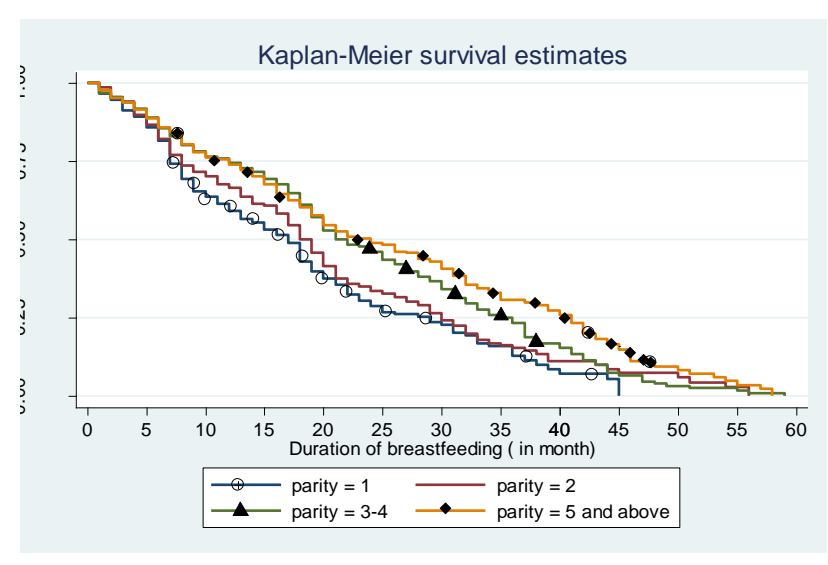

Figure 1: Survival functions for women who are continuing breastfeeding at different level of parity, Bihar, India 2005-2006.

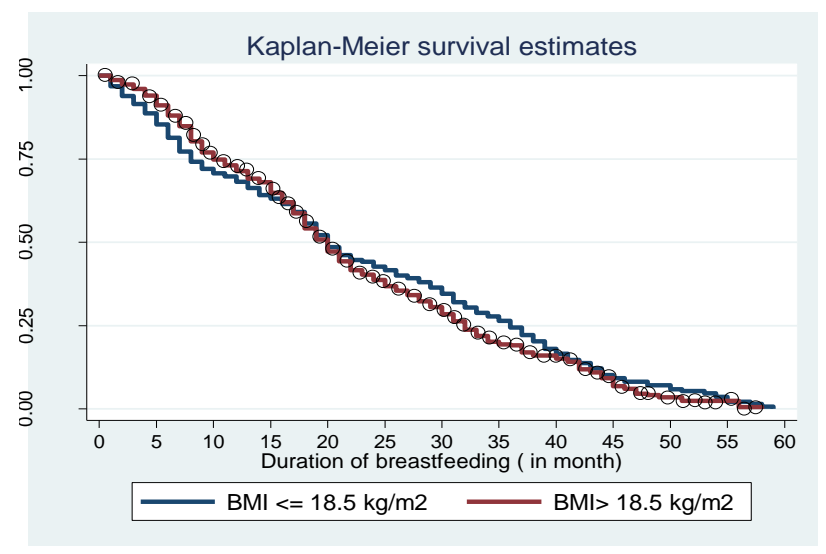

Figure 2: Survival functions for women who are continuing breastfeeding at different level of body mass index, Bihar, India 2005-2006.

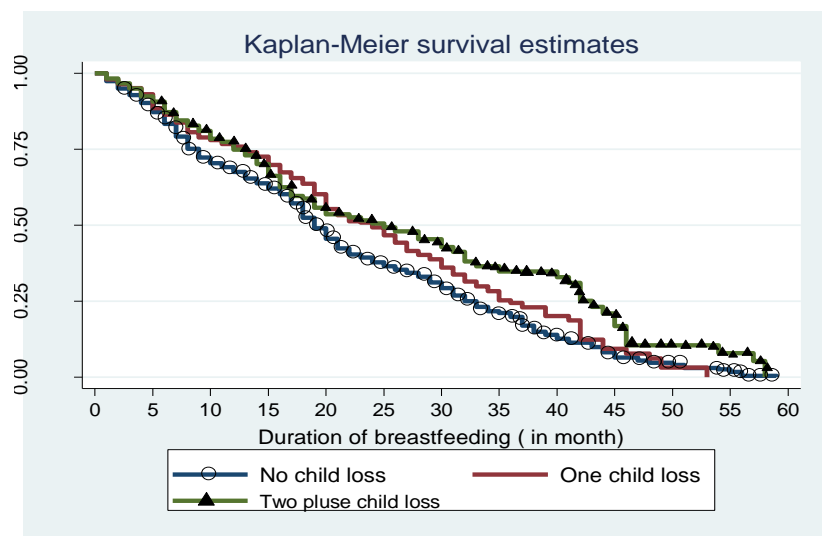

Figure 3: Survival functions for women who are continuing breastfeeding by survival status of child, Bihar, India 2005-2006.

\section{Mean duration of postpartum amenorrhea (PPA)}

The mean survival of postpartum amenorrhea by different months of breastfeeding according to Kaplan Meier, in Bihar, India is shown in Table 3.

It is found that the duration of postpartum amenorrhea is increasing but fluctuating by the different interval of breastfeeding. There is no effect on postpartum amenorrhea interval of breastfeeding less than 3 months. The postpartum amenorrhea period increases with duration of breastfeeding from 4-6 months to 25 months and above. Women who had breastfeed 4 to 6 months, their survival mean duration time is less than 9 months. The survival functions also decrease rapidly over time. Women who had breastfeed their children for lower duration of breastfeeding has the faster resumption of menstruation during the first six months, subsequent 
point survival functions tends to slow down steadily, duration of PPA decreased substantially up to 24 months by 12 month differences, after that point the function decreased steadily (Figure 4). Figure 5 shows that survival function of postpartum amenorrhea by the parity of women. The postpartum amenorrhea period is increases with increasing parity. The curve is substantially increases up to 23 months afterwards it is decreasing. Figure 6 gives the duration of postpartum amenorrhea at different level of body mass index. The women who were having low or normal body mass index had similar declining survival function. In this transition, mother's BMI is highly significant and in the expected direction.

Table 3: Survival mean of postpartum amenorrhea of women by different months of breastfeeding according to Kaplan Meier, Bihar, India 2005-2006.

\begin{tabular}{|c|c|c|c|c|}
\hline \multirow{2}{*}{ Duration of breastfeeding } & \multicolumn{2}{|l|}{ Mean } & \multicolumn{2}{|l|}{ Median } \\
\hline & Estimate & $95 \% \mathrm{CI}$ & Estimate & $95 \% \mathrm{CI}$ \\
\hline $0-3$ months & 0.657 & $(0.480-0.835)$ & 0.08 & \\
\hline 4-6 months & 8.987 & $(7.034-10.941)$ & 8.0 & $(4.277-11.723)$ \\
\hline 7-9 months & 7.711 & $(6.373-9.049)$ & 8.0 & $(6.018-9.982)$ \\
\hline $10-12$ months & 8.493 & $(5.144-11.842)$ & 6.0 & $(3.735-8.265)$ \\
\hline 13-15 months & 6.893 & $(5.682-8.104)$ & 6.0 & $(4.104-7.896)$ \\
\hline 16-18 months & 9.393 & $(8.040-10.745)$ & 8.0 & $(6.183-9.817)$ \\
\hline 19-21 months & 8.525 & $(7.225-9.825)$ & 8.0 & $(5.316-10.684)$ \\
\hline 22-24 months & 10.092 & $(8.332-11.851)$ & 8.0 & $(6.653-9.347)$ \\
\hline $25+$ months & 11.544 & $(10.320-12.768)$ & 10.0 & $(9.162-10.838)$ \\
\hline Log Rank (Mantel-Cox) & \multicolumn{4}{|c|}{ Chi-Square $\chi^{2}(2372.966), \mathrm{P}<.001$} \\
\hline
\end{tabular}

Test of equality of survival distributions for the different levels of duration of breastfeeding.

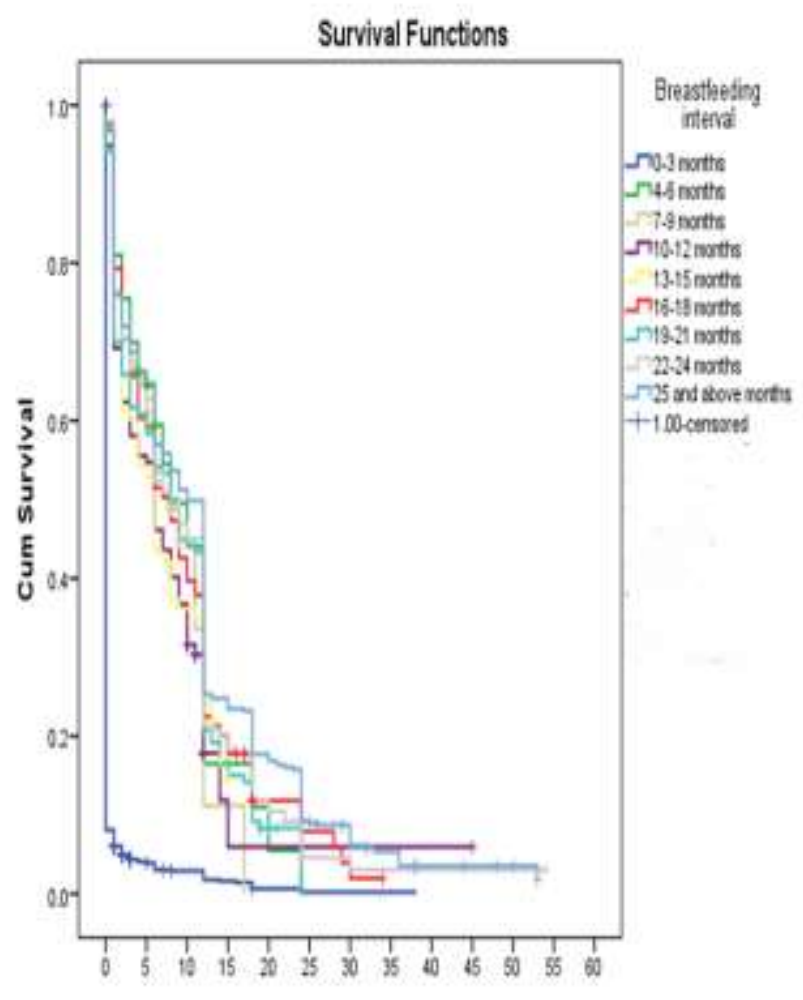

Figure 4: Survival functions for women who are continuing postpartum amenorrhea at different months of breastfeeding interval, Bihar, India 20052006.

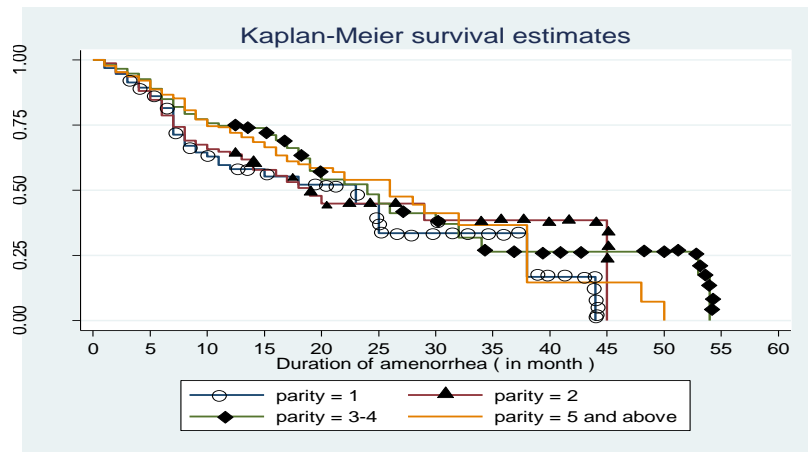

Figure 5: Survival functions for women who are continuing duration of postpartum amenorrhea at different level of parity, Bihar, India 2005-2006.

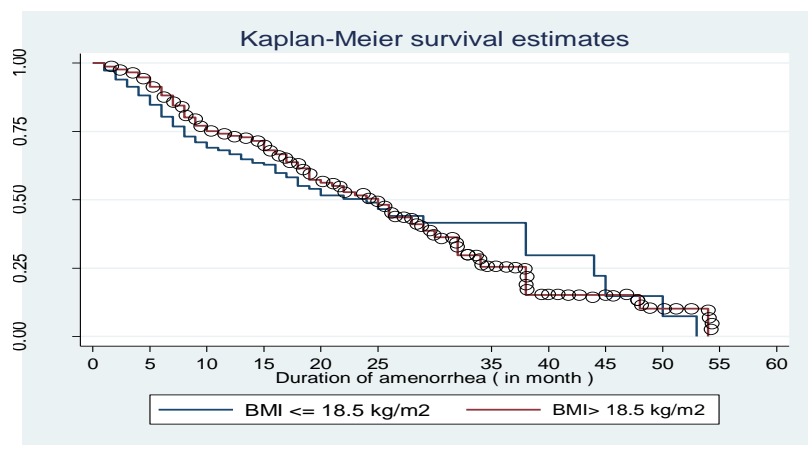

Figure 6: Survival functions for women who are continuing duration of postpartum amenorrhea at different level BMI, Bihar, India 2005-2006. 
Mothers with a BMI greater than $18.5 \mathrm{~kg} / \mathrm{m}^{2}$ resume ovulation faster than those with a lower BMI and the mothers who receive high amounts of supplements resume menses faster.

\section{Mean duration of postpartum amenorrhea (PPA) by background characteristics of women}

Table 4 shows the mean for postpartum amenorrhea by the background characteristics of women in Bihar, India. The length of interval of breastfeeding has a long impact on the duration of amenorrhea. It is found that the length of breastfeeding is having an increasing effect on postpartum amenorrhea, which means the longer duration of breastfeeding leads to longer duration of postpartum amenorrhea. The mean postpartum amenorrhea period increases from 1 month in case of breastfeeding interval of less than 5 months to 12 months in case of 25 months and above. The parity of the women and sex of the child is having slightly an increasing effect on postpartum amenorrhea. The mean for survival time is not much longer in case of female as compared to male. A child's sex had no effect on duration of PPA, suggesting that, in this setting, mothers invested in daughters and sons equally through breastfeeding but in case of residence, rural women have higher mean for survival time than urban women.

Use of contraception is also playing an important role in increasing mean for duration of postpartum amenorrhea. The women who are not using contraception have small mean as compared to women who are using any contraceptive method. There are no much differences in mean for survival time by religion.

Hindu and Muslim women have nearly same mean for survival time except women from other religious groups. The women who were not educated are having higher mean for survival time (duration of amenorrhea) and it is decreasing with increasing education. Age of mother is an important factor for survival duration of PPA, at low level of age the mean for survival time is low, the mean survival times are increasing with increasing age of mother, at pick age of child bearing i.e. 20-24 years to 25-29 years and it is declining first slowly at the age 30 34 years and then rapidly at the older ages (35 and above). Similarly, in case of age at first marriage is also an important factor for survival duration of post-partum amenorrhea period. The mean survival times are increasing with increasing age at first marriage, at younger age ( $<19$ years) 5 months to older age (30 years and above) 6 months. Child loss is having an effect on the mean duration of PPA to women who have one child loss. The mother with no child loss and two or more children is having less mean for survival time as compared to women who have one child loss.
Table 4: Kaplan-Meier mean duration of postpartum amenorrhea by some selected background characteristics of women in Bihar, India 2005-2006.

\begin{tabular}{|c|c|c|}
\hline $\begin{array}{l}\text { Women's } \\
\text { Background }\end{array}$ & $\begin{array}{l}\text { Mean for } \\
\text { survival } \\
\text { time }\end{array}$ & $\begin{array}{l}95 \% \\
\text { Confidence } \\
\text { Interval }\end{array}$ \\
\hline \multicolumn{3}{|l|}{ Breastfeeding } \\
\hline $0-5$ months & 1.008 & $(0.79-1.226)$ \\
\hline 6-12 months & 8.839 & $(6.729-10.949)$ \\
\hline 13-24 months & 9.442 & $(8.471-10.412)$ \\
\hline 25 months and above & 11.544 & $(10.32-12.768)$ \\
\hline \multicolumn{3}{|l|}{ Parity of women } \\
\hline Parity 1 & 5.311 & $(4.425-6.198)$ \\
\hline Parity 2 & 5.459 & $(4.642-6.275)$ \\
\hline Parity 3-4 & 5.584 & $(4.887-6.281)$ \\
\hline Parity 5 and above & 5.658 & $(4.959-6.357)$ \\
\hline \multicolumn{3}{|l|}{ Sex of child } \\
\hline Male & 5.504 & $(4.972-6.036)$ \\
\hline Female & 5.774 & $(5.165-6.382)$ \\
\hline \multicolumn{3}{|l|}{ Residence } \\
\hline Urban & 2.464 & $(2.16-2.767)$ \\
\hline Rural & 5.023 & $(4.584-5.462)$ \\
\hline \multicolumn{3}{|l|}{ Use of contraception } \\
\hline Not use & 3.916 & $(3.557-4.275)$ \\
\hline Use & 4.156 & $(3.677-4.635)$ \\
\hline \multicolumn{3}{|l|}{ Religion } \\
\hline Hindu & 4.052 & $(3.71-4.395)$ \\
\hline Muslim & 4.027 & $(3.453-4.6)$ \\
\hline Other & 0.364 & $(0-0.91)$ \\
\hline \multicolumn{3}{|l|}{ Education level } \\
\hline No education & 5.196 & $(4.742-5.651)$ \\
\hline Primary & 3.317 & $(2.672-3.962)$ \\
\hline Secondary & 2.566 & $(2.113-3.018)$ \\
\hline Higher & 1.304 & $(0.87-1.738)$ \\
\hline \multicolumn{3}{|l|}{ Age of the mother } \\
\hline$<19$ years & 1.127 & $(0.84-1.414)$ \\
\hline 20-24 years & 5.89 & $(5.116-6.664)$ \\
\hline $25-29$ years & 7.856 & $(6.952-8.759)$ \\
\hline $30-34$ years & 5.265 & $(4.495-6.035)$ \\
\hline 35 years and above & 2.204 & $(1.769-2.638)$ \\
\hline \multicolumn{3}{|l|}{ Age at first marriage } \\
\hline$<19$ years & 4.994 & $(4.622-5.366)$ \\
\hline 20-24 years & 3.374 & $(2.364-4.384)$ \\
\hline $25-29$ years & 1.432 & $(0.458-2.406)$ \\
\hline 30 years and above & 6.0 & $(0-17.76)$ \\
\hline \multicolumn{3}{|l|}{ Child loss } \\
\hline No loss & 3.764 & $(3.425-4.103)$ \\
\hline One loss & 4.983 & $(4.24-5.726)$ \\
\hline Two or more & 4.534 & $(3.578-5.489)$ \\
\hline
\end{tabular}

Relative risk on breastfeeding with women's selected background characteristics

The simultaneous and independent effects that the covariates considered in analysis have on the stop of 
breastfeeding can be assess through the multivariate proportional hazard regression model. The coefficient associate with covariate describes the relationship between them and the risk of stop breastfeeding at every time. Their interpretation as a value is rather difficult, but their signs give us sufficient information about the direction in which the risk is changing. A positive sign of coefficient indicates an increase in the risk and negative sign means a decrease in the risk of stop breastfeeding. Further, by exponentiation these regression coefficients we are able to calculate the relative risks associated with the covariate in equation. Values greater than one mean that the relative risk of stop breastfeeding is greater for this group when compared with the reference group. Values less than one indicate the risk is lower for the group being analyzed when compared with the baseline group. Socio-economic and demographic factors associated with duration of breastfeeding are presented in the Table 5 .

Table 5: Cox proportional hazard model estimates of relative risk by some selected background characteristics on breastfeeding, Bihar, India 2005-2006.

\begin{tabular}{|c|c|c|c|}
\hline Background characteristics & Relative risk & $P$ value & 95\% Confidence interval \\
\hline \multicolumn{4}{|l|}{ Age of mother } \\
\hline$<19$ years $\AA$ & 1 & $\ldots \ldots$ & \\
\hline 20-24 years & $1.908 * *$ & 0.005 & $(1.217-2.989)$ \\
\hline $25-29$ years & $3.728 * * *$ & 0.000 & $(2.376-5.849)$ \\
\hline 30 years and above & $10.078 * * *$ & 0 & $(6.419-15.822)$ \\
\hline \multicolumn{4}{|l|}{ Sex of child } \\
\hline Male ${ }^{\circledR}$ & 1 & $\ldots \ldots$ & \\
\hline Female & 0.996 & 0.939 & $(0.904-1.098)$ \\
\hline \multicolumn{4}{|l|}{ Parity of mother } \\
\hline Parity $1 \circledR$ & 1 & $\ldots \ldots$ & \\
\hline Parity 2 & $0.654 * * *$ & 0 & $(0.535-0.799)$ \\
\hline Parity 3-4 & $0.530 * * *$ & 0 & $(0.433-0.647)$ \\
\hline Parity 5 and above & $0.397 * * *$ & 0 & $(0.317-0.497)$ \\
\hline \multicolumn{4}{|l|}{ Residence } \\
\hline Urban ${ }^{\circledR}$ & 1 & $\ldots \ldots$ & \\
\hline Rural & 0.917 & .109 & $(.825-1.020)$ \\
\hline \multicolumn{4}{|l|}{ Religion } \\
\hline Hindu ${ }^{\circledR}$ & 1 & 0.617 & $(0.842-1.108)$ \\
\hline Muslim & 0.966 & 0.583 & $(0.583-2.613)$ \\
\hline Other & 1.234 & & \\
\hline \multicolumn{4}{|l|}{ Education level } \\
\hline No Education ${ }^{\circledR}$ & 1 & $\ldots \ldots$ & \\
\hline Primary & 1.080 & 0.380 & $(0.910-1.282)$ \\
\hline Secondary & $1.196^{* *}$ & 0.008 & $(1.048-1.365)$ \\
\hline Higher & 1.034 & 0.807 & $(0.791-1.352)$ \\
\hline \multicolumn{4}{|l|}{ Child loss } \\
\hline No child loss ${ }^{\circledR}$ & 1 & $\ldots \ldots$ & \\
\hline One child loss & $1.154 *$ & 0.022 & $(1.021-1.304)$ \\
\hline Two plus child loss & 1.139 & 0.125 & $(0.965 \pm 1.345)$ \\
\hline \multicolumn{4}{|l|}{ Age at first birth } \\
\hline$<19$ years ${ }^{\circledR}$ & 1 & $\ldots \ldots$ & \\
\hline $20-24$ years & $0.809 * * *$ & 0 & $(0.721-0.908)$ \\
\hline 25-29 years & $0.568 * * *$ & 0 & $(0.429-0.752)$ \\
\hline 30 and above & 0.546 & 0.063 & $(0.289-1.033)$ \\
\hline \multicolumn{4}{|l|}{ Contraceptive use } \\
\hline Use ${ }^{\circledR}$ & 1 & $\ldots \ldots$ & \\
\hline Not use & $1.160 * *$ & 0.008 & $(1.040-1.293)$ \\
\hline \multicolumn{4}{|l|}{ Delivery status } \\
\hline Caesarean ${ }^{\circledR}$ & 1 & $\ldots \ldots$ & \\
\hline Normal & 0.884 & 0.56 & $(0.585-1.337)$ \\
\hline \multicolumn{4}{|l|}{ Working status } \\
\hline Working® & 1 & $\ldots \ldots$ & \\
\hline Not working & 1.024 & 0.686 & $(0.913-1.148)$ \\
\hline
\end{tabular}

Significance: $* * * \mathrm{p}<0.001, * * \mathrm{p}<0.01, * \mathrm{p}<0.05$, ® is the reference category. 
The proportional hazard analysis has identified that mother age, age at first birth, parity of mother, education of mother ,contraceptive use and status of child survival are play a significant role on the risk of termination of breastfeeding while sex of child, residence, religion, delivery status, working status are found insignificant effect.

Those women who are at younger age ( $<19$ years) and (20-24 years) had a lower risk to stop breastfeeding as compared to women with older age after controlling for all covariates included in the model. After the age 30 years women have 10 times at risk of stop breastfeeding as compared to younger women (less than 19 years). In case of sex of the child, there is no much difference in breastfeeding pattern among the women. Residence does not play a significant role in risk to stop breastfeeding practices among women in Bihar. There is no much difference in rural and urban areas. Parity of women plays a highly significant role, after controlling to all the covariate in the model. There are less risks of women at parity two $(35 \%)$, at parity 3 to $4(53 \%)$ and parity 5 and above $(39 \%)$ with compared to the reference group parity one. So the parity of women is the highly significant at all the level of parity. Religion is not playing a very significant role in duration of breastfeeding; all are at the same level of breastfeeding practices among the women. The risk of stop breastfeeding increased with increasing maternal education; as compared to illiterate women, the risk of stop breastfeeding is positive. In case primary and higher educated women the risk are similar like illiterate women, but at the secondary level of education, it is (19\%) higher with the reference category. Survival status of child plays a significant impact on the duration of breastfeeding. The risk of stop breastfeeding is found to be more than $15 \%$ in case of women who experience one child loss, $13 \%$ in case of women who have more than two children loss than women who have no experience of child loss.

A negative and strong association is found between duration of breastfeeding and age at first birth of mother. When controlled other covariates the age at first marriage and taken age less than 19 years as a reference then the risk of stop breastfeeding is decreasing (by $22 \%$ in case of 20-24 years and 44\% in case of age group 25-29 years) with increasing age at first birth of mother. There is a variation in duration of breastfeeding among contraceptive users and non-users. Those women who are using contraceptive have $16 \%$ more risk of stop breastfeeding as compared to women those are not using any method of contraception. Mothers who deliver their child in the normal way reported $22 \%$ less likely to terminate breastfeeding than the mothers who deliver their child in the caesarean situation. Working women are more likely to breastfeed for a slightly longer duration as compared with their non-working counterparts.

\section{Effect of background characteristics on the duration of post-partum amenorrhea (PPA)}

To assess the partial effect of the explanatory variables on the duration of postpartum amenorrhea while controlling all the other covariates, a multivariate proportional hazard model is performed. The results are presented in Table 6 . After the adjustment of other covariates under study, the duration of breastfeeding has a negative association with the risk of returns to menses. The value of relative risk is found in negative direction of duration of breastfeeding categories from low to high. It is found that the longer duration of breastfeeding leads to longer duration of PPA.

Table 6: Cox proportional hazard model estimates of relative risk of socio-demographic characteristics and effect of breastfeeding variables on post-partum amenorrhea, Bihar, India 2005-2006.

\begin{tabular}{|c|c|c|c|}
\hline $\begin{array}{l}\text { Background } \\
\text { characteristics }\end{array}$ & $\begin{array}{l}\text { Relative } \\
\text { risk }\end{array}$ & $P$ value & $95 \% \mathrm{CI}$ \\
\hline \multicolumn{4}{|c|}{ Duration of breastfeeding } \\
\hline $0-5 \AA$ months & 1 & $\ldots .$. & \\
\hline $6-12$ months & 1.128 & 0.181 & $(0.946-1.342)$ \\
\hline 13-24 months & $1.201^{*}$ & 0.009 & $(1.046-1.380)$ \\
\hline $\begin{array}{l}25 \text { and above } \\
\text { months }\end{array}$ & $0.216 * * *$ & 0 & $(0.189-0.247)$ \\
\hline \multicolumn{4}{|c|}{ Parity of mother } \\
\hline Parity $1 \circledR$ & 1 & ........ & \\
\hline Parity 2 & $0.748 * * *$ & 0 & $(0.667-0.839)$ \\
\hline Parity 3-4 & $0.720 * * *$ & 0 & $(0.652-0.795)$ \\
\hline $\begin{array}{l}\text { Parity } 5 \text { and } \\
\text { above }\end{array}$ & $0.701 * * *$ & 0 & $(0.635-0.775)$ \\
\hline \multicolumn{4}{|l|}{ Residence } \\
\hline Urban ${ }^{\circledR}$ & 1 & ....... & \\
\hline Rural & $0.901 *$ & 0.003 & $(0.840-0.966)$ \\
\hline \multicolumn{4}{|c|}{ Contraceptive use } \\
\hline Not use ${ }^{\circledR}$ & 1 & ........ & \\
\hline use & $1.217 * * *$ & 0 & $(1.123-1.318)$ \\
\hline
\end{tabular}

By considering 0-5 months of breastfeeding interval as a reference category the risk of menses are increasing by $13 \%$ in case of breastfeeding interval 6-12 months. The findings also shows that the risk of menses are increasing by $20 \%$ in case of breastfeeding interval 13-24 months by controlling other covariate in the model, $(\mathrm{RR}=1.20$ $, \mathrm{p}<0.05)$.

The risk of menses are significantly decreasing by $88 \%$ in case of breastfeeding interval is 25 months and above $(\mathrm{RR}=0.216, \mathrm{p}<0.001)$ with the reference category. In fact, for every one month increase in duration of breastfeeding, the risk of resumption of menses decreases. The coefficients are found highly significant for the current reporting data sets of mother by last but at least one child birth. The increase in parity are found with 
decrease in the relative risk of postpartum amenorrhea indicates that mothers those who have higher parity have experienced longer duration of postpartum amenorrhea.

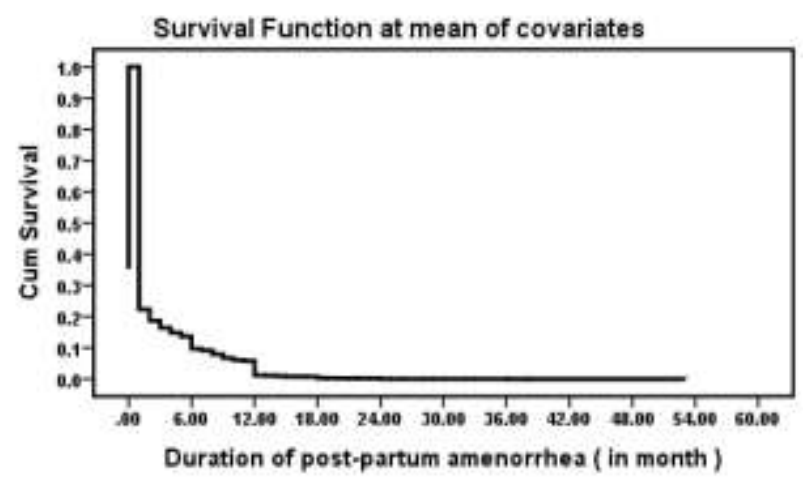

Figure 7: Survival functions at mean of covariate for women who are continuing duration of postpartum amenorrhea, Bihar, 2005-2006.

There is nearly one-fourth less chance of relative risk in women who have at parity level one as compared with women who have zero parity, in case of 3-4 children (28\%) and more than 5 children (30\%) have less relative risk of PPA period. Residence of women shows insignificant association with the duration of postpartum amenorrhea period. There is only $10 \%$ less risk of PPA in rural women as compared to urban women. Contraception also plays an insignificant role in the duration of PPA period. Women who are using any contraceptive method have $22 \%$ higher relative risk of postpartum amenorrhea period as compared to women who are not using any contraceptive method.

\section{DISCUSSION}

The multivariate analysis of determinants of duration of postpartum amenorrhea among women in Bihar has been investigated in relation to characteristics of mother and her child indicate that the duration of breastfeeding, parity, contraceptive use, residence, survival status of child, age of mother, age at first birth, age at first marriage, religion, residence, sex of child, education level, economic activity, delivery status directly or indirectly impact on the duration of postpartum amenorrhea study also support the study by Singh SN in 1993, Sivakami M in 2003, Srinivasan K in $1989 .{ }^{18-20}$ This study indicates that around $65 \%$ of women had never used any contraception. Majority of women were breastfeeding their children for shorter duration of less than 5 months. Half of the women were having more than 3 children. Mean survival for duration of breastfeeding by the parity of women decreases from the low parity to high parity of the women.

The women belonging to poorest and poorer wealth index categories have high mean survival for breastfeeding and low in case of richest wealth quintile. Age of mother, age at first birth, survival status of child, parity, education, contraceptive use have a significant impact on duration of breastfeeding. Relative risk of stop breastfeeding are decreasing by increasing parity of women, age at first birth, normal delivery status and increasing by age of mother, education, child loss, use of contraceptive and not working condition. Sex of child, religion and residence are not having much impact on duration of breastfeeding practices among women. Women with at least secondary schooling have greater probabilities of earlier stop breastfeeding than those with lower formal education, after controlling for all the remaining variables. $^{21-23}$ The finding shows that $20 \%$ of risk in decreasing breastfeeding interval 13-24 months and 21\% in 25 months and above.

Among the demographic variable two important variables are associated with resumption of menses: parity and use of contraception. Increased parity substantially reduces the risk of resuming menses after controlling for all the other factors. Duration of breastfeeding, parity, residence, contraceptive use have a significant impact on duration of PPA and empirical evidence indicates that longer and more frequent breastfeeding may increase the length of an ovulatory period. Mothers with a BMI greater than $18.5 \mathrm{~kg} / \mathrm{m}^{2}$ resume ovulation faster and high mean for duration of breastfeeding than those with a lower BMI. The use of contraception also increases the risk of resuming menstruation earlier. That is women who used contraception methods are more likely to resume menses than women who did not use contraception.

\section{CONCLUSION}

The direction despite the results obtained in this study, breastfeeding cannot be expected to automatically reduce fertility in all circumstances for individual women, particularly among most modern segments of population, especially in countries/states where the practice of contraception is not widespread. Intervention programs aimed at increasing natural contraceptive method like PPA and use may need to involve different approaches, including promoting couples' discussion of fertility preferences and natural family planning, improving women's self-efficacy in negotiating sexual activity and increasing their breastfeeding practices. Policies are needed to encourage the rural families to give their girls a chance of attending higher level education then women can get better knowledge to benefit of breastfeeding practices and PPA gap. In consequence postpartum infertility associated with breastfeeding practices are important factors, which reduces overall fertility levels.

\section{Limitation of study}

From the available data of NFHS-3 we tried to estimate a reliable and valid result. But it is not free from all bias. The analysis has been carried out separately for duration of PPA and duration of breastfeeding following the birth of the last born child. Some explanatory variables, which were interrelated, are excluded from the multivariate 
hazard modelling to avoid multicollinearity between the variables. This study may not be generalized for whole India due to some regional differences in women characteristics. It is applicable for only Bihar, India.

\section{Funding: No funding sources}

Conflict of interest: None declared

Ethical approval: The study was approved by the Institutional Ethics Committee

\section{REFERENCES}

1. Davis K, Blake J. Social structures and fertility: an analytical framework. Economic Development and Cultural Change. 1956;4(2):117-21.

2. Aryal TR. Differential of breastfeeding among rural women of western Nepal: A survival analysis. Journal of Nepal Health Research Council. 2005;3(2):58-64.

3. Bongaarts J, Potter R. Fertility, Biology and Behavioral: An analysis of the proximate determinants. Acedemic Press, New York. 1983.

4. Nath DC, Goswami G. The socio-demographic correlates of post-partum amenorrhoea in an urban society of India. Genus. 1996;52(1-2):105-23.

5. Islam MN, Islam. Biological and behavioral determinants of fertility in Bangladesh: Bangladesh Fertility Survey, Secondary Analysis, edited by Cleland et al. 1993;13(2):29-72.

6. Henry L. Some Data on Natural Fertility. Eugenics Quarterly. 1961;8(6):81-91.

7. Bongaarts J. A framework for analyzing the proximate determinants of fertility. Population and Development Review. 1978;4(1):105-32.

8. Bongaarts J. The proximate determinants of natural marital fertility. In Determinants of Fertility in Developing Countries.Vol.1. Supply and Demand for Children, RA Bulato, RD Lee, eds., Acedemic Press, New York, (1983); 20 (1)103-138.

9. Potter RG, Kobrin F. Distribution of amenorrhea and an ovulation. Population Studies. 1981;35(1):85-94.

10. Ahamed MM. Breastfeeding in Bangladesh. J. Biosoc Sci. 1986;18(4):425-34.

11. Huffman SL, Chowdhury A, Allen H, Nahar L. Suckling patterns and post-partum amenorrhea in Bangladesh. J Biosoc Sci. 1987;19(2):171-9.

12. Yadava KNS, Jain SK. Post-partum amenorrhoea in rural Eastern Uttar Pradesh, India. J Biosoc Sci. 1998;30(2):227-43.
13. PintO, Guido. Breastfeeding and Postpartum Amenorrhea among Bolivian Women: A Survival Analysis. CDE Working Paper No.2005-01. 2005;94-22.

14. Islam S, Yadava KNS, Alam MA. Differentials and Determinants of the duration of breastfeeding in Bangladesh: A multivariate analysis, Pruc. Pakistan Acad Sci. 2006;43(1):1-14.

15. International Institute for Population Sciences (IIPS). National Family Health Survey (NFHS-3), India. 2006;3(1):173-4.

16. Cox DR. Regression models and life tables (with discussion). Journal of Bio-social Science. 1989;21(3):365.

17. Primary Census abstract on Census of India-2011. Registrar General of India (RGI), New Delhi. 2011:22-3.

18. Singh SN .Breastfeeding and its Effects on Fertility. Center of Population Studies, Banaras Hindu University, Varanasi. 1993;3(2):145-53.

19. Sivakami M. The impact of maternal work participation on duration of breast feeding among poor women of south India. Asia Pac Popul J. 2003;18(3):69-90.

20. Srinivasan K, Pathak KB and Pandey A .Determinants of Breastfeeding and Postpartum amenorrhoea in Orissa. J Biosoc Sci. 1989;21(1):365-71.

21. Dwivedi LK, Priyanka D .Relationship Between Breastfeeding and Postpartum Amenorrhea among Indian Women: An Epidemiological Appraisal. African Journal of Basic \& Applied Sciences. 2012;4(2):30-7.

22. Sarkar S. Socio-demographic Differentials and Determinants of Contraception Methods Choice among currently married women in India. International Institute for Population Sciences.

23. Velankar DH. Knowledge, Attitude and Practices Regarding Contraceptive Methods of Family Planning in an Urban. Bombay Hospital Journal. 2009;51(2):149-54.

Cite this article as: Brajesh, Ranjan M, Nagdeve DA, Shekhar C. Determinants and differentials of postpartum amenorrhea associated with breastfeeding among women in Bihar, India. Int J Reprod Contracept Obstet Gynecol 2016;5:154-65. 